\section{What price blue weeds?}

Australia is clearing more native vegetation than any other developed country according to Krockenberger (1998). Between 1991 and 1995 almost $5000 \mathrm{sq} \mathrm{km}$ were cleared to make way for urban expansion, tourism development, cattle grazing, cotton and cereal growing, sugar production and horticulture. An estimated 1000-2000 birds, some of them threatened species, are killed for every 100 ha of land cleared. Inestimable numbers of other animals are also killed. While controls on land clearing have been introduced in some Australian states, they are not well enforced and loopholes allow clearance to continue at a rate far in excess of the federal government's aim of revegetating 250,00 ha per annum.

What would make a difference? Improved legislation and better enforcement? Maybe. But the main problem would seem to be, as in many parts of the world, that if landholders can profit from the clearance for whatever purpose it will be hard to stop them, or gain their support. For examples of this I do not have to look further than the area where I live, where a farmer ploughed up an area of species-rich chalk grassland, a habitat disappearing fast in the UK. He did it to plant a subsidized crop, despite protests from conservationists and even though the area was a Site of Special Scientific Interest.

What if people wanting to clear native vegetation were to be taxed on its real value and that tax were to be used to purchase, restore or enhance native habitats? But to do that one would have to calculate the value of native plants and birds, or lizards and butterflies.

I am reminded of a boy I met 20 years ago. He was one of a class of 9-year-olds from a town in southern England. It was a glorious spring day and I was leading a field class in the Sussex countryside. We entered a wood carpeted with bluebells Hyacinthoides nonscripta. Their heady fragrance filled the air. We stopped, the class gathered round and I asked the children what they could see. 'Trees', they chorused. 'What about the plants under the trees?' I asked. Silence. Then the boy said, tentatively, 'Blue weeds?'
I was not surprised that none of the class knew the name for bluebells, but the term 'weed' made me think. It has different meaning for different people in different contexts, but generally implies something worthless.

If a developer were to apply for permission to clear that wood for a golf course, there would be, no doubt, local protest but no way to put an economic value on those bluebells. The outcome might or might not be in the developer's favour, depending on political will. Is that boy of 20 years ago now sitting on a local council that would rule on such matters? Does he still feel the same about blue weeds?

Also almost 20 years ago, I read a book (van Dieren and Hummelinck, 1979) that attacked classical economics for its failure to take into account the value of nature. It argued that if nature could be defined or assessed by values that are accepted in economic and political decision-making, then it would be preserved and respected. Going back to the woodland and leaving aside the value of the bluebells and the ecological functions the woodland performs, how could we assess its recreational value? If that wood were cleared, according to van Dieren and Hummelinck (1979), people using it for recreational purposes would need an equivalent alternative and the cost of providing this would equal its recreational value. Added to this could be the air-purifying effect of the trees and what it would cost to replace this function. A 100-year-old beech tree, for instance can remove several hundred kilogrammes of particulate matter from the air.

Like the small boy, people do not always know that they need nature, do not know how important it is or how to value it. This lack of insight will have to be remedied if we are to prevent the continuing world-wide loss of nature's capital.

Jacqui Morris, Editor

\section{References}

Dieren, W. van. and Hummelinck, M.G.W. 1979 Nature's Price. The Economics of Mother Earth. Marion Boyars, London and New York.

Krockenberger, M. 1998. Habitat (Australian Conservation Foundation), 26 (1), supplement. 